\title{
Razão e zombaria em Shaftesbury
}

\author{
Luís F. S. N ascimento
}

doutorando na Universidade de São Paulo

resumo Sensus Communis: An Essay on the Freedom of Wit and Humour é o segundo de um conjunto de seis tratados que Anthony Ashley Cooper publicou em $1711 \mathrm{com}$ 0 nome de Characteristicks of Men, Manners, Opinions, Times. 0 presente artigo busca analisar a estreita relação que os conceitos de "razão" e "zombaria" assumem nesta obra e a sua importância para a elaboração da noção shaftesburiana de "senso comum".

palavras-chave Shaftesbury - senso comum - razão - zombaria - humor - engenho

Em que sentido podemos estabelecer um vínculo entre a noção shaftesburiana de "razão" e aquela de "zombaria" (R aillery) apresentada em Sensus $C$ ommunis: $A \cap E$ ssay on the $F$ reedom of $W$ it and $H$ umour? A primeira dificuldade que aqui se apresenta é a impossibilidade de definir com precisão o que vem a ser zombaria. De acordo com Shaftesbury, "descrever a verdadeira zombaria seria matéria tão difícil e talvez de tão pouco proveito quanto definir a boa educação" (SH AFTESBU RY, 1999a, p. 40; grifos no original). A relação entre zombaria e boa educação não é fortuita e a ela Shaftesbury retorna quando nos diz: "Em um cavalheiro, nós reconhecemos o gracejo e a zombaria como sendo administrados sempre com boa educação e jamais de modo grosseiro ou apalhaçado [C lownish]" (idem, p. 41).

É preciso ser polido quando não se quer agir como um daqueles zelotes ( $Z$ ealots) que não suportam a mínima zombaria a respeito de suas

R ecebido em novembro de 2004. A ceito em janeiro de 2005.

doispontos, Curitiba, vol. 1, n. 2, p.167-176, jan/ jun, 2005 


\section{8}

opiniões e pensam que um tema (Subject) sério apenas pode ser tratado por uma via solene, "embora possam estar satisfeitos em tratar de outra maneira 0 que um outro considera sério e solene e precipitam-se a pôr à prova do ridículo qualquer opinião, exceto as deles próprios" (idem, p. 38; grifos no original).

A relação entre zombaria e boa educação revela um bom uso da via zombeteira. Como comenta M árcio Suzuki, o que aqui está em causa é saber em que medida a zombaria pode ser justa (fair) - em que sentido ela é benéfica para uma conversa particular e para a sociabilidade em geral e não um mero meio de diminuir e escarnecer um adversário. A via zombeteira é justa, escreve Suzuki, "se vale, indiscriminadamente, para todos" (SU ZU KI, 2004, p. 7). É o livre emprego da zombaria que dará a sua boa medida, uma vez que não há como prescrever regras para esse uso justo ou defini-lo com precisão1. É no próprio convívio social, no interior de uma conversa entre amigos (em que ninguém é rígido o suficiente para não deixar que suas opiniões passem pelo crivo do ridículo) que a zombaria se ajusta: torna se fair. Somente a sociedade educa e faz 0 homem polido: "Toda polidez é devida à liberdade. N ós nos polimos uns aos outros e lustramos nossos cantos e lados ásperos por uma sorte de colisão amigável. R estringir isso é trazer, inevitavelmente, ferrugem ao entendimento dos homens. É destruir a civilidade, a boa educação e mesmo a própria caridade, sob a pretensão de mantê-la" (SH AFTESBU RY, 1999a, p. 39-40; grifos no original).

Livres para dialogar, colidindo amigavelmente uns com os outros, os homens encontram e exercem a polidez. Como mostra Shaftesbury, esse foi o caso da conversa que ele menciona no início de Sensus $C$ ommunis. Embora a referida discussão tenha terminado abruptamente e "em uma tal sorte de confusão, a ponto de levar a quase nada o que quer que havia sido avançado anteriormente no discurso" (idem, p. 41), não obstante 0 fato de ali "muitos esquemas grandiosos e finos" (ibidem) terem sido destruídos e "muitos raciocínios sérios subvertidos" (ibidem), tudo isso foi feito sem ofender as partes concorrentes.

À defesa desse tipo de conversa em que os amigos discorrem livre e alegremente sobre diversos temas, sem a obrigação de uma definição precisa a respeito deles, Shaftesbury acrescenta o seguinte comentário:" $E$ estou persuadido de que, se a própria razão tivesse julgado seu próprio 
interesse, ela teria considerado que receberia mais vantagens dessa via simples e familiar do que da usual e rígida aderência a uma opinião particular" (idem, p. 41-42).

Imaginando que 0 amigo para quem escreve Sensus $C$ ommunis oporse-á a essa concepção de razão que se adapta melhor a um modelo de conversa entre amigos, ao invés de fixar-se em uma opinião particular e determinada, o filósofo inglês elabora uma resposta que nos será muito importante para a compreensão de sua noção de razão: "A isso eu respondo que, de acordo com a noção que tenho de razão, nem os tratados escritos dos eruditos, nem os rígidos discursos dos oradores, são capazes de ensinar por eles mesmos o uso dela [razão]. É apenas o hábito de raciocinar que pode fazer aquele que radiocina [R easoner]. $E$ os homens jamais podem ser melhores convidados ao hábito do que quando sentem prazer nisso. U ma liberdade [F reedom] de zombaria, uma liberdade [L iberty] na linguagem decente para questionar cada coisa e uma permissão para desembaraçar [unravelling] ou refutar qualquer argumento sem ofensa ao argüidor, são os únicos termos que podem tornar uma tal conversa especulativa agradável de qualquer modo. Para dizer a verdade, elas têm-se tornado incômodas para a humanidade pela rigidez das leis prescritas a elas e pelo prevalente pedantismo e fanatismo daqueles que nelas reinam e assumem serem, para eles próprios, os ditadores nessa província" (idem, p. 42).

Toda ditadura, qualquer imposição de regras, é prejudicial ao raciocínio. A razão faz-se no hábito, no mero exercício de raciocinar. A zombaria tem aqui um papel muito importante: ela torna-se signo desse prazer tão benéfico para o $R$ easoner. A o zombarmos das coisas, ao vermos o que há de ridículo nelas, estamos livres para questioná-las. É preciso, diz-se Shaftesbury, que levemos em conta vários pontos de vista a partir dos quais podemos entender um tema (um Subject). É necessário que lancemos várias luzes e iluminemos de diversas maneiras os objetos de nosso raciocínio - aquilo que apenas se mostra sob uma única luz permanecerá duvidoso. A via do ridículo e da zombaria permite-nos ver as coisas sob um outro aspecto, dá-nos a possibilidade de inverter a maneira como as vemos e confere vida e alegria ao hábito especulativo que caracteriza a razão. 0 "estado humorado da mente" (GR EAN , 1967, p. 121), diz-nos G rean, é oposto à mentalidade dogmática. N esse sentido, 
a presença da zombaria nessa concepção de razão torna-a o oposto de uma raz ão reta: restringir-se a um único caminho ou via, por mais seguro ou reto que pareça, é limitar a investigação e o conhecimento do tema sobre o qual se raciocina; é, na expressão de Shaftesbury, enferrujar 0 entendimento dos homens e, em última instância, desconhecer o que há de essencial na razão: "Tornamo-nos melhores arraz oadores [R easoners] ao raciocinarmos agradavelmente e em nossa comodidade, tomando e dispondo [laying down] esses assuntos tal como quisermos" (SH AFTESBU RY, 1999a, p. 46; grifo no original).

A razão, portanto, aperfeiçoa-se ao proceder agradavelmente, largando e dispondo seus subjects da maneira que considera mais adequada e cômoda. Esse desregramento ou aparente displicência ao raciocinar também aparece em um conhecido trecho das M iscelâneas: "O s célebres engenhos da raça [R ace] miscelânea, os escritores de ensaios, os oradores casuais, os inventores de reflexão, os criadores de meditação e outros escritores de gênero irregular podem defender-se com a sua peculiar vantagem 'de seguir a variedade da natureza'. E em um tal clima como o nosso, sua defesa pode ser, sem dúvida, muito justa. $N$ ós, insulares, afamados por outras mutabilidades, somos particularmente notados pela variedade e inconstância de nosso clima. E se o nosso gosto nas letras é responsável por essa temperatura [Temperature] de nosso clima, é que, a nosso ver, um escritor tem de ter mais valor em seu gênero quanto mais agradavelmente surpreender seu leitor, por mudanças e transportes súbitos que o levem de um extremo ao outro" (SH AFTESBU RY, 1999b, p. 174-175; grifos no original).

Q uando lemos essa passagem podemos pensar que esse caráter variá vel, essa irregularidade ao pensar e escrever apenas diz respeito às $M$ iscelâneas, último e sexto tratado das $C$ aracterísticas e que pode ser lido como "um arremate crítico a elas [C aracterísticas]" (SU ZU KI, 2004, p. 8), uma vez que comenta e analisa os cinco tratados precedentes. Parece ser uma exclusividade das $M$ iscelâneas estabelecer vínculos e relações entre os diversos temas tratados ao longo das $\mathrm{C}$ aracterísticas. $\mathrm{N}$ o entanto, basta-nos passar os olhos em algumas das muitas páginas que compõem os seis tratados para percebermos que esse procedimento já estava funcionando por toda a obra. Seja lá qual for o tratado que estejamos lendo, há sempre al gumas notas de pé de página que nos remete a um outro tratado, seja ele 
antecedente ou precedente. Assim, por exemplo, quando, em Sensus Communis, Shaftesbury fala do diálogo como gênero literário que mais caracterizava a A ntigüidade, ele acrescenta uma nota que faz referência a uma parte do Solilóquio ${ }^{2}$ - justamente 0 trecho em que, nesse tratado, 0 tema do diálogo é discutido. Esse recurso é freqüente nas $C$ aracterísticas, e não há um só dos seis tratados que não faça referência a um ou mais dos outros por via de notas de rodapé. Pois bem, o que quer o filósofo inglês com isso, senão mostrar que esses temas são tratados de diferentes maneiras ou vias ao longo das $C$ araderísticas? 0 que é isso senão lançar diferentes luzes sobre um determinado subject (o diálogo, por exemplo), buscando compreendê-lo melhor? D esse ponto de vista, as $C$ aracterísticas, como um todo, também poderiam ser entendidas como diferentes luzes que são lançadas sobre um determinado número de temas. Por certo, esse procedimento, essa variação que permite ver as coisas sob diversos aspectos, fica mais evidente, abandona os pés de página e ganha o corpo do texto nas $M$ iscelâneas, mas esses transportes súbitos que lembram a irregularidade do clima insular já estão presentes nos tratados anteriores e, de certa forma, já anunciavam e exigiam a elaboração mais detalhada dos vínculos e relações entre os cinco primeiros tratados que as M iscelâneas apresentam.

Como nos mostram os comentadores do filósofo inglês, a razão em Shaftesbury é discursiva ou dialógica3. Fabiénne Brugère lembra-nos de que a etimologia latina do termo "discurso" é discurrere, um discorrer que nos remete à imagem de uma conversa casual, circunstancial, sem rigidez ou desregrada (BRUGÈRE, 1999, p. 99). Em um primeiro momento, essa idéia de um mero discorrer parece ir ao encontro da de razão, visto que o raciocínio, a exemplo do que foi dito no trecho citado das $M$ iscelâneas, varia tanto quanto 0 tempo da Grã-Bretanha. À razão é essencial a liberdade de humor, de poder zombar e de ver o ridículo das coisas sobre as quais julga - como vimos, é assim que ela atua e aperfeiçoa-se. $M$ as essa liberdade que permite a variação e os súbitos transportes de que nos fala as $M$ iscelâneas pode ser entendida como sinônimo de acaso e desregramento? 0 fato de essa razão não prescrever nenhuma regra fixa faz dela algo completamente circunstancial, sem rumo ou direção? Será que o discurso shaftesburiano é menos rigoroso quando não é tão rígido ao definir noções como as de "zombaria", "humor", "senso comum", "engenho" e até mesmo a de "razão"? 
De acordo com filósofo inglês, existe uma regra ou ordem no modo como a mente e a razão procedem que, não obstante 0 fato de não poderem ser provadas ou demonstradas como se faz, por exemplo, em $M$ atemática, expressam-se e deixam-se mostrar nas múltiplas ocorrências ou manifestações daquilo que é justo, elegante e nobre: "O s modelos de casas, prédios e seus ornamentos, que os acompanham; os planos de jardins e seus compartimentos; a ordenação de caminhos, plantações e alamedas e mil outras simetrias ocorrem no espaço dessa mais feliz e elevada simetria ou ordem da mente. As espécies de justeza, nobreza e elegância mostrar-se-ão em mil ocasiões e em mil temas" (SHAFTESBU RY, 1999a, p. 76; grifos no original).

A aparente irregularidade do processo racional acaba revelando, ele mesmo e nele mesmo, a ordem que o direciona. Sem estabelecer nenhuma regra anterior e externa ao seu próprio movimento, a razão sempre atua com um senso de justeza e busca aperfeiçoar o modo (way) com que pensa os seus subjects. 0 raciocínio é um hábito que se auto-regula. A via do humor e zombaria representa aqui um papel fundamental: ela é, como indica Laurent Jaffro, uma instância de crítica e de exame inerente ao processo de autoconstituição da razão (JAFFR O, 1998, p. 98-99). N ão se pode, então, entender esse exame crítico como algo estranho à razão; ele faz-se com ela e nela. "A crítica", diz-nos M árcio Suzuki, "não tem pressa"; diferentemente do dogmático e do cético, o crítico "sabe que não se deve precipitar na adesão a uma seita, partido ou sistema" (SU ZU KI, 2004, p. 23). N o que tange à razão, não se trata, portanto, de um simples discorrer casual ou sem rumo, mas do próprio exame crítico que jamais se apressa e sempre dispensa dogmas ou verdades já estabelecidas. Justamente 0 que parecia mais displicente na razão shaftesburiana (as variações, os desvios, os transportes, a ausência de definições precisas e mesmo o elogio da zombaria), mostra-se agora como signo de sua seriedade e rigor. Por trás de tantas digressões, vemos o trabalho meticuloso da crítica. M esmo a filosofia mais árida ( $D$ ry), mesmo aqueles que tentam congelar o raciocínio e colocá-lo em uma única via reta e segura, terão de admitir a natureza livre e auto-reguladora da razão. $U$ ma vez que também é livre, o leitor de Shaftesbury sabe muito bem, como nos mostra a M iscelâneaV , que as "variações climáticas" presentes em sua obra são a expressão da liberdade e do rigor de seu raciocínio. $A$ M iscelânea $V$ 
apresenta-nos uma concepção dinâmica de leitor: no lugar de prescrever princípios ou regras de conduta, o filósofo inglês visa a estabelecer uma conversa com aquele que o lê. Ao leitor basta saber que 0 escritor não tem o lugar de honra (place of $\mathrm{H}$ onour), que ele não pode simplesmente aceitar de antemão o gosto (Taste) e o juízo (Judgement) do autor. A queles leitores que ignoram isso, "não apenas traem a eles mesmos, mas também a causa comum do autor e do leitor, o interesse pelas letras e pelo conhecimento e a principal liberdade, privilégio e prerrogativa da parte racional do gênero humano" (SH AFT ESBU RY, 1999b, p. 248; itálicos e negritos no original).

A "principal liberdade, privilégio e prerrogativa da parte racional do gênero humano" é formar uma comunidade, um senso comum. U m "lugar" em que as diferentes opiniões e posturas fortalecem os laços daqueles que se comunicam: "Se 0 senso comum exprime a presunção de um acordo, é na experiência do desacordo que ele se descobre, pois todo desacordo, na medida em que é expresso e comunicado, supõe um acordo mínimo" (JAFFR O, 1998, p. 105).

0 desacordo não apenas é benéfico para a comunidade: ele é necessário, já que nos mostra algo incontestável: não obstante as diferentes opiniões e crenças, os homens continuam a comunicar-se. Q uando tentam encontrar o que haveria de comum entre os homens, 0 autor de Sensus $C$ ommunis e os amigos que com ele conversam não chegam a nenhuma conclusão satisfatória: em moral, em política, em religião e em outros tantos assuntos, eles não encontram nenhum consenso - há várias opiniões acerca desses temas. Todos os amigos admitem a existência de um ponto de acordo entre os homens, mas a" questão que ainda se punha era: onde?" (SH AFTESBU RY, 1999a, p. 46; grifo no original). A solução de Shaftesbury é, então, mostrar que o lugar do senso comum não é o mesmo do das opiniões: "H ouve um tempo em que os homens eram apenas considerados por suas ações e comportamentos. Suas opiniões eram deixadas para eles mesmos. Eles tinham a liberdade para diferir tanto nessas [opiniões] quanto em suas faces. C ada qual tomava 0 ar e a aparência que Ihe fossem mais naturais. $M$ as, com o tempo, foi considerado decente corrigir as feições dos homens e tornar suas compleições intelectuais uniformes e de uma sorte apenas. Assim, o magistrado tornou-se alguém que veste [D resser] e, por sua vez, também foi vestido 


\section{4}

assim como merecia quando cedeu seu poder a uma nova ordem de criados" (idem, p. 48-49; grifos no original).

$N$ ão apenas a ordem da razão é prejudicada com a imposição de regras severas, como também a ordem social. Privado de sua liberdade, sem o direito de vestir-se ou ter a cara que mais lhe agrada, o homem torna-se melancólico. Seu humor fica grosseiro e seu senso de comunhão é deturpado. $\mathrm{N}$ ão é de admirar que a própria idéia de "senso comum" acabe por tranfformar-se em uma noção confusa e passe a ser considera da como uma questão de opinião, ao contrário do que ocorria outrora. Como não deixa de mostrar-nos o próprio título de Sensus $C$ ommunis, é a concepção latina que Shaftesbury tem em mente ao falar da boa noção de comunidade (cf. LAR TH O M AS, 1985, p. 450; JAFFR O, 1998, p. 108), aquela que não visava a uniformizar os seus membros e que convivia com os mais diversos ares, feições e compleições. De acordo com filósofo inglês, diferentemente do que se pensa na modernidade, o senso comum não é outra coisa senão o "amor pelo gênero humano" (SH AFTESBU RY, 1999a, p. 68): a própria noção que os homens têm naturalmente de um acordo com outros membros de sua espécie. Para Shaftesbury, é só porque existe desde sempre na natureza humana esse senso comum que os homens organizam-se em sociedades, ordens civis, governos e estados: "A união civil ou confederação jamais poderia tornar-se certa ou errada se elas não subsistissem anteriormente" (idem, p. 61).

Shaftesbury descarta a idéia de um contrato anterior à sociedade e que a instauraria; ele refuta qual quer outra explicação para a formação da ordem social e civil que não o fato de existir nos homens esse, digamos, "espírito de sociabilidade". Para o bem ou para o mal, de modo certo ou errado, todos os governos, os estados, as confederações, os partidos etc., são derivações desse espírito comum e maior que naturalmente une 0 gênero humano. Para explicar-nos o que entende por natureza, o autor de Sensus $C$ ommunis dá-nos o seguinte princípio: "que se al guma coisa é natural, em alguma criatura ou gênero, é aquilo que é o preservativo do próprio gênero e conduz ao seu próprio bem-estar e manutenção" (ibidem; grifo no original). A definição de natureza é, então, muito simples e quase redundante: é o que é natural ou o que garante a preservação de uma determinada criatura ou espécie. É tão natural ao homem falar, arrebanhar-se, formar clãs e tribos quanto comer e beber. Eis 0 
ponto em que pessoas de opiniões opostas, de diferentes clãs e culturas, se unem: todos são orientados por uma mesma natureza comum. I sso parece tão simples para Shaftesbury que chega a ser difícil para ele entender como os homens puderam-no esquecer. Como essa noção de senso comum foi tão deturpada e, por vezes, ignorada pela modernidade? Ele responde-nos que: "Essa comunidade maior não se enquadra facilmente no olho. Tampouco o interesse nacional ou aquele de todo um povo, ou de um corpo político são apreendidos tão prontamente" (idem, p. 62; grifos no original).

A visão da totalidade não é algo que obtemos facilmente; é preciso refinar e aguçar 0 olhar. D aí a necessidade dos dubs, pequenas sociedades em que 0 vínculo e a familiaridade entre as pessoas deixam mais evidente algo que é comum a todos os homens. "Formar cantões", escreve Shaftesbury, "é natural quando a sociedade cresce demais e maciçamente" (idem, p. 63; grifo no original). 0 que não podemos esquecer é que os cantões, assim como os partidos e os governos, são expressões de um único "princípio combinante" (combining P rinciple) (idem, p. 62).Todo homem tem sua parcela desse princípio e "aqueles que são de faculdade mais jovial e ativa têm um quinhão maior disso [desse princípio]" (ibidem). 0 homem de engenho e humor, aquele que com seus amigos cultiva e torna polida a sua razão, é capaz de ver as coisas sob várias luzes e, por isso, sabe que o seu clube é uma manifestação limitada e parcial de algo bem maior: a natureza humana. $\mathrm{N}$ ão por acaso, 0 autor das M iscelâneas dizia-nos, nas primeiras linhas do trecho que citamos, que a grande vantagem de seu gênero literário estava em seguir as "variações da natureza" (idem, p. 174-175).

1 "Como ocorre nos outros textos do autor [Shaftesbury], o que se quer evidenciar aqui é a impossibilidade de se transmitir essas noções [zombaria, boa educação, engenho, senso comum, humor etc.] nas formas filosóficas convencionais (tratado, investigação etc.). Elas não são objetos de definição, de dedução ou demonstração; não são ensinamentos técnicos ou científicos, que podem ser passados adiante simplesmente respeitando as boas normas de pedagogia" (SU ZU KI, 2004, p. 8).

2 Trata-se da segunda nota de Sensus C ommunis, Seção V da Parte I (SH AFTESBU RY, 1999a, p. 44).

doispontos, Curitiba, vol. 1, n. 2, p.167-176, jan/ jun, 2005 


\section{6}

3 Laurent Jaffro, Jean-Paul Larthomas, Stanley G rean, Fabienne B rugère e M árcio Suzuki são alguns dos comentadores que estabelecem essa relação entre razão e discurso em Shaftesbury.

\section{Referências bibliográficas}

BRU GÉR E, F. 1999. T héorie de l'art et philosophie de la sociabilité selon Shaftesbury. Paris: H onoré C hampion.

GR EAN , S. 1967. Shaftesbury's P hilosophy of R eligion and E thics: A Study in Enthusiasm. $O$ haio: 0 xford $U$ niversity.

JAFFR O, L. 1998. É thique de la communication et art d'écire - Shaftesbury et les Lumiéres anglaises. Paris: PU F.

LART H O M AS, J. P. 1985. D e Shaftesbury a K ant. Paris: Didier Érudition.

SH AFT ESBU RY. 1999a. Sensus C ommunis: An Essay on the Freedom of $W$ it and Humour. In: C haracteristicks of men, manners, times. Ed. by P. Ayres. O xford: Clarendon. 1999b. M iscellaenous reflections. In: men, manners, times Ed. by P. Ayres. O xford: Clarendon. . C haraderisticks of

SU ZU KI, M . 2004. Q uem ri por último, ri melhor - humor, riso e sátira no "Século das Luzes". Terceira M argem, R io de Janeiro, n. 10, p. 7-27. 